\title{
CHEMICAL PROFILE OF THE ESSENTIAL OILS OF CHILEAN BOLDO SAMPLES (Peumus boldus Molina) SOLD IN RIO DE JANEIRO CITY
}

\author{
Gisele Santos de Souza ${ }^{3}$, Xavier Maia Mariano ${ }^{1}$; Júlia Lima Isnard ${ }^{2}$; Wanderson \\ Fernando Mello de Souza ${ }^{1,3}$; Cristiane Barbosa Rocha ${ }^{3}$; Ricardo Felipe Alves Moreira ${ }^{1,3}$ \\ (gisalsouzza@gmail.com)
}

\footnotetext{
${ }^{1}$ Food and Nutrition Postgraduate Program (PPGAN) - UNIRIO, Brazil

${ }^{2}$ Institute of Biosciences, Federal University of the State of Rio de Janeiro (UNIRIO), Brazil

${ }^{3}$ Biomedical Institute, Federal University of the State of Rio de Janeiro (UNIRIO), Brazil
}

Chilean boldo (Peumus boldus Molina) is a native plant of the central and southern regions of Chile. This plant belongs to the Monimiaceae family. This herb is widely consumed in Brazil and in several other countries of the world due to its broad spectrum of pharmacological effects: colagogue, antioxidant, anti-inflammatory, hepatoprotective, antimicrobial, antifungal, anthelmintic and diuretic actions. These pharmacological properties and some of its toxic effects are obviously associated with the chemical composition of its leaves. In this respect, the essential oil components of these leaves are among the main active ingredients of this herb. Thus, the aim of this study was to evaluate the chemical composition of the essential oils of Chilean boldo samples that were sold in the Rio de Janeiro city packed on sachets [group 1 (G1): five samples] or plastic bags [group 2 (G2): five samples]. The essential oils were extracted by hydrodistillation. These oils were analyzed by gas chromatography (GC) combined with a flame ionization detector (FID) or mass spectrometry (MS). Separation was achieved on a fused silica SPB-1 capillary column. Fifty-five (55) compounds have been identified based on mass spectra data, standard compounds co-elution and retention indexes. Their relative amounts were assumed to be proportional to the areas under the corresponding chromatogram peaks. The cis- $\beta$-ocimene, $\delta$-cadinene, palustrol, isoaromadendrene epoxide, santalol and isolongifolol were identified by the first time as Chilean boldo components. The chemical profile of the essential oils obtained from the samples of G1 was qualitatively and quantitatively very similar to the profile of the essential oils coming from the samples of G2. This similarity between their chemical profiles may indicate a single source for the plants used to produce such commercial samples. The presence (in high concentrations) of three important chemical markers of the Chilean boldo essential oils [ascaridole $-\mathrm{G} 1=(25.54 \pm 13.53) \%, \mathrm{G} 2=$ $(30.31 \pm 10.46) \% ; 1,8$-cineole $-\mathrm{G} 1=(12.29 \pm 2.57) \%, \mathrm{G} 2=(14.07 \pm 3.91) \% ; p$-cymene $-\mathrm{G} 1$ $=(10.68 \pm 2.26) \% ; \mathrm{G} 2=(11.30 \pm 1.01) \%]$ suggests that the samples are genuine. 1,8-Cineole, $p$-cymene and terpinen-4-ol could be characterized as odor active compounds in these samples.

Keywords: Chilean boldo, essential oils, volatile fraction. 